\title{
An unusual cause of breathlessness in a young man
}

\author{
Antony Leslie Innasimuthu MD MRCP ${ }^{1}$, Rajiv Sankarnarayanan MBBS MRCP $2 *$, \\ Gopala Krishna B Rao FRCP ${ }^{1}$, Rob S Hornung FRCP ${ }^{1}$
}

\begin{abstract}
AL Innasimuthu, R Sankarnarayanan, GKB Rao, RS Hornung. An unusual cause of breathlessness in a young man. Can J Cardiol 2009;25(6):369-371.

Amphetamine abuse is a common problem in the developed world. Cardiomyopathy secondary to amphetamine abuse is rare in the general population. The present report describes a 34-year-old man who presented with shortness of breath. Following further investigations, the cause of his breathlessness was determined to be amphetamine abuse. The incidence of amphetamine abuse and its cardiac sequelae are reviewed. The mechanism of amphetamine-induced dilated cardiomyopathy is analyzed, with further review of its complications and treatment.
\end{abstract}

Key Words: Amphetamine; Dilated cardiomyopathy; Heart failure

\section{Cause inhabituelle d'essoufflement chez un homme jeune}

La consommation abusive d'amphétamines est un problème courant en Occident. La cardiomyopathie liée aux amphétamines est rare dans la population générale. Le présent rapport décrit le cas d'un homme de 34 ans qui a consulté pour essoufflement. Des examens approfondis ont révélé que son essoufflement était causé par une consommation excessive d'amphétamines. L'article fait le point sur l'incidence du phénomène et de ses complications cardiaques. L'auteur explique en outre le mécanisme de la cardiomyopathie dilatée liée aux amphétamines, ses complications et son traitement.

\section{$\mathrm{T}$ he present report describes an unusual case of dilated cardiomyo- pathy in a young man caused by chronic amphetamine abuse. The literature regarding amphetamine-induced cardiomyopathy has been reviewed and we believe that amphetamine may have been underesti- mated as a factor in the etiology of dilated cardiomyopathy.}

\section{CASE PRESENTATION}

A previously physically fit 34-year-old man was admitted with a twoweek history of central chest tightness associated with shortness of breath and fatigue. His shortness of breath occurred with approximately $1.6 \mathrm{~km}$ of physical exertion (New York Heart Association functional class 2). The chest tightness was nonexertional and nonpleuritic, with no radiation. There was no history of orthopnea or ankle swelling. There was no history suggestive of antecedent flu-like illness or myocarditis. He was a smoker with a 15 pack-year history and his alcohol intake was approximately 30 units per week. There was also a history of drug abuse, mainly with an oral intake of up to $\$ 9$ worth of amphetamine (approximately $300 \mathrm{mg}$ of purity $35 \%$ ), taken daily for more than 17 years. He was not on any regularly prescribed medications and did not have a history of chemotherapy. There was no family history of cardiomyopathy or other heart disease. General and systemic examinations were unremarkable. His electrocardiogram showed $\mathrm{T}$ wave inversion in the lateral leads (Figure 1). His chest $\mathrm{x}$-ray showed cardiomegaly but his lung fields were clear. His hemogram, renal function, liver function tests (LFTs), thyroid function test and C-reactive protein were normal. The serology tests to detect myopericarditis were normal. His troponin $\mathrm{T}$ was negative. Echocardiography showed that all chambers were dilated with severe global left ventricular dysfunction (Figures 2 and 3). It showed moderate mitral regurgitation, trace tricuspid regurgitation, and normal aortic and pulmonary valves. His pulmonary artery V2 maximum was $66 \mathrm{~cm} / \mathrm{s}$ and he had an ejection fraction of $25 \%$. He was started on acetylsalicylic acid, diuretics, an angiotensinconverting enzyme inhibitor and a beta-blocker. He improved symptomatically over a period of one month. He was advised to abstain completely from both alcohol and amphetamines. He declined referral to a drug rehabilitation program. Outpatient follow-up was planned for further investigation with cardiac catheterization and coronary angiography, but he did not attend.

\section{DISCUSSION}

While ischemic heart disease is the most common cause of left ventricular dysfunction, our patient did not have any features of ischemic heart disease or associated risk factors. Furthermore, his echocardiogram did not show a regional wall motion abnormality. Despite the consumption of 30 units of alcohol per week, his LFTs and mean corpuscular volume were normal. As shown by Alterman et al (1) in 1990 , alcoholic cardiomyopathy is unlikely when the mean corpuscular volume and LFT are normal. Therefore, the cardiomyopathy in the present case was thought to have been caused by chronic amphetamine abuse, possibly potentiated by alcohol.

Amphetamine abuse is prevalent in the United Kingdom. It is the second most 'confiscated' drug after cannabis. Recent surveys by the European Monitoring Centre for Drugs and Drug Addiction showed that, among young adults (15 to 34 years of age), experience with amphetamine use ranges from $0.1 \%$ to $10 \%$, with the United Kingdom reporting an exceptionally high rate of $16.5 \%$ (2). The number of seizures, as well as the quantity of drug seized, have been steadily increasing, with the United Kingdom being the leading country (2).

\footnotetext{
${ }^{1}$ Department of Cardiology, University Hospital Aintree, Liverpool; ${ }^{2}$ Department of Cardiology, Taunton and Somerset Hospital, Taunton, United Kingdom

*Both authors contributed equally

Correspondence: Mr Antony Leslie Innasimuthu, Aintree Cardiac Centre, University Hospital Aintree, Lower Lane, Liverpool L9 7AL, United Kingdom.

Telephone 44-0151-529-2584, fax 44-0151-529-2724, e-mail antonyleslie@yahoo.co.in

Received for publication November 15, 2006. Accepted March 31, 2007
} 


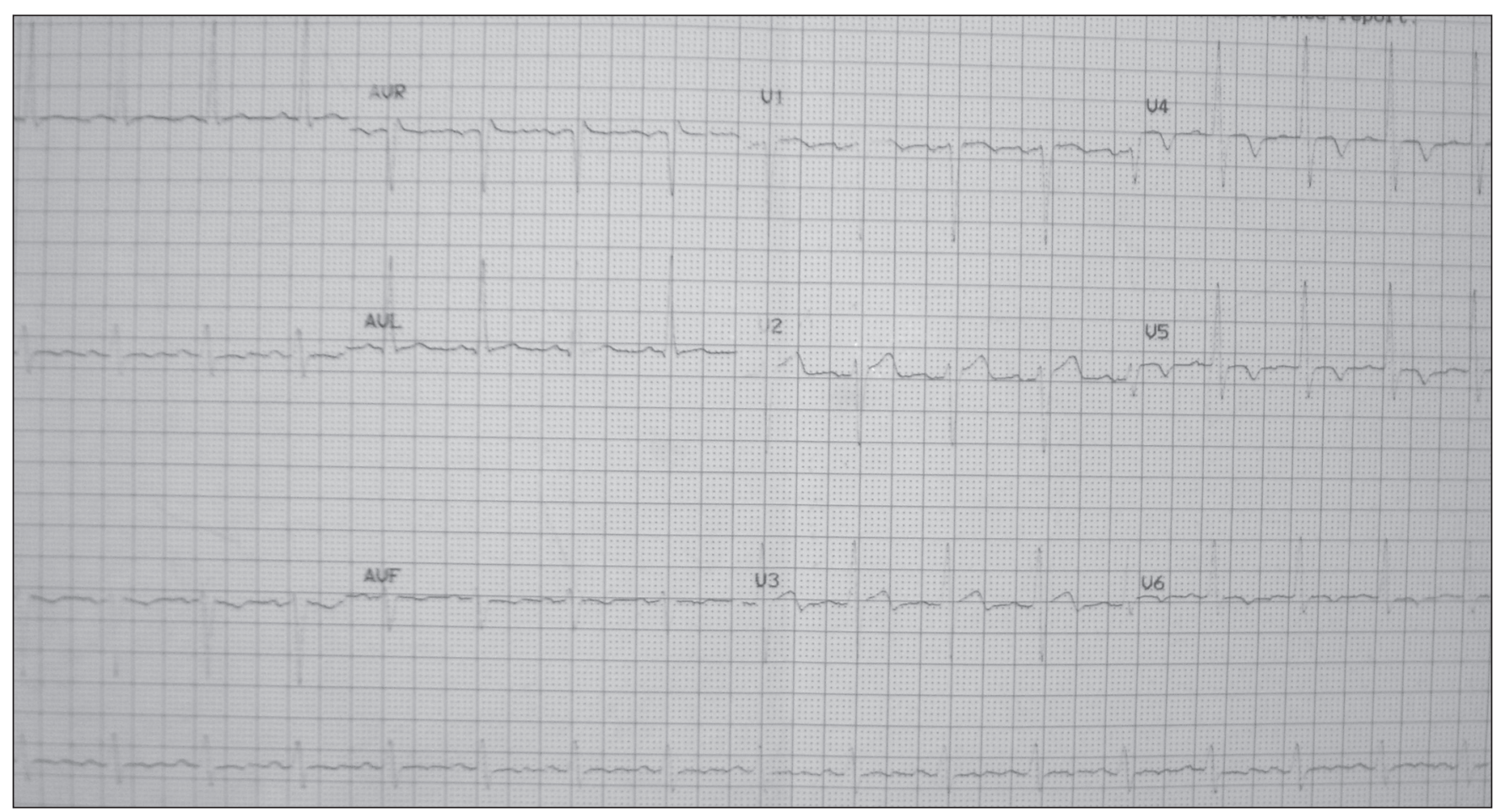

Figure 1) Electrocardiogram showing $T$ wave inversion in the lateral leads

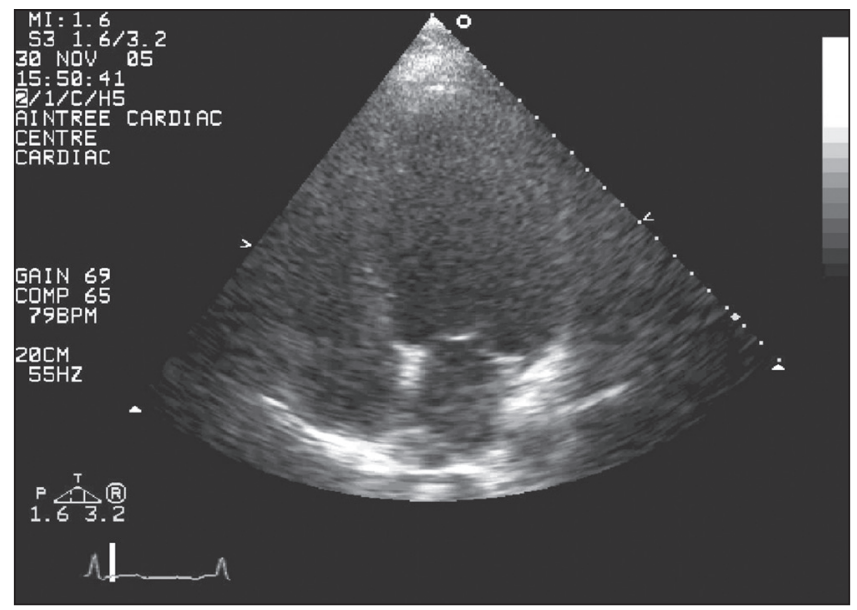

Figure 2) Echocardiography showing that all chambers were dilated, with severe global left ventricular dysfunction

Amphetamines can be ingested orally, inhaled or, less commonly, injected intravenously. It is readily absorbed from both the nasal mucosa and the gastrointestinal tract, and freely penetrates the bloodbrain barrier. The plasma half-life is variable and it can be detected in the urine for several days after ingestion (2).

As shown by Ghuran and Nolan (3), amphetamine produces indirect sympathetic activation by releasing noradrenaline, dopamine and serotonin from terminals in the central and autonomic nervous systems. This sympathetic activation can cause diffuse or local coronary artery spasm, leading to chest pain (as in our patient) or even myocardial infarction. Amphetamine toxicity is potentiated when it is taken with alcohol. Alcohol is a vasodilator and leads to tachycardia, further increasing the workload on the heart, which is already stressed by sympathetic activation due to amphetamine use. Alcohol also increases amphetamine levels by inhibiting its breakdown, thus having the potential to enhance all of amphetamine's cardiotoxic effects. Hypertension is common, but severe hypotension (due to paradoxical

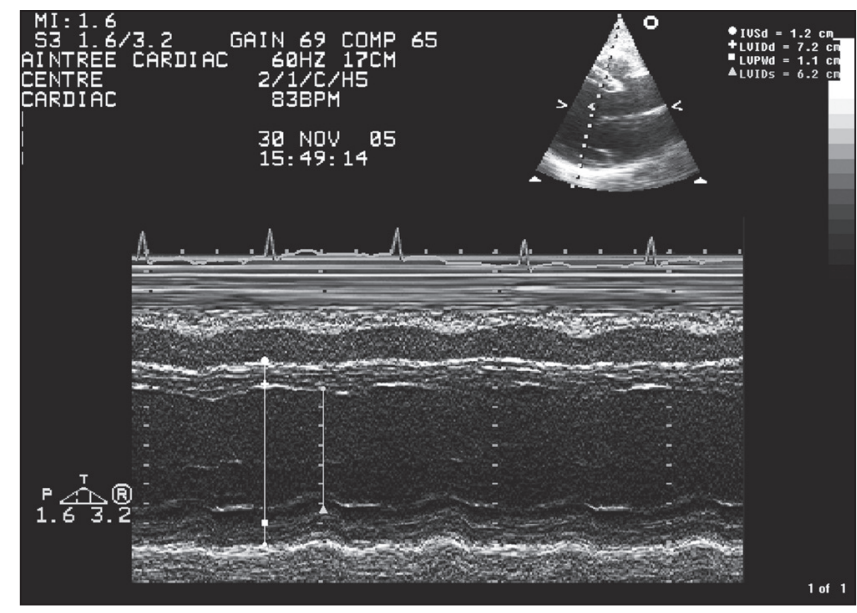

Figure 3) M-mode echocardiogram showing a dilated left ventricle

central sympathetic suppression or suppression of vasomotor flow) can also occur (4). Prolonged administration of these sympathomimetic agents may be associated with dilated cardiomyopathy. Possible etiological mechanisms include subendocardial ischemia, fibrosis and myocyte necrosis (3), monoamine oxidase and mitochondrial abnormalities. A retrospective study (5) of 1640 patients admitted with cardiomyopathy identified 20 patients in whom cardiomyopathy could be attributed to methamphetamine use. The degree of left ventricular failure could be severe enough to lead to cardiac failure and death despite therapy (5). It is difficult to establish a dose range of chronic amphetamine intake required to cause cardiomyopathy from the cases reported in the literature.

Due to the sympathetic stimulation, there is also an increased risk for supraventricular and ventricular tachyarrhythmias. The presence of myocardial ischemia, fibrotic bands and left ventricular hypertrophy may be a further substrate for the tachyarrhythmias of the re-entry type. Sudden death can occur in patients using excessive 
amphetamine as a result of myocardial ischemia, infarction, arrhythmias and acute heart failure (2).

The treatment of amphetamine-induced dilated cardiomyopathy is the same as any other cause of heart failure due to cardiomyopathy diuretics, angiotensin-converting enzyme inhibitors and beta-blockers. The cases reported in the literature suggest that standard therapy is appropriate and, in most instances, abstinence from the drug will lead to an improvement in cardiovascular function, both clinically and on serial imaging (2).

\section{CONCLUSION}

Amphetamine-induced cardiomyopathy is likely to be increasingly recognized in younger age groups and should be considered once the usual differential diagnosis of dilated cardiomyopathy has been excluded. A combination of psychosocial support (including abstinence and rehabilitation) and medical management is essential.

\section{REFERENCES}

1. Alterman AI, McLellan AT, Searles JS, Wang RY. Alcohol abuse in patients with dilated cardiomyopathy. Laboratory vs clinical detection. Arch Intern Med 1990;150:1079-82.

2. European Monitoring Centre for Drugs and Drug Addiction. 2006 Annual Report on the State of the Drugs Problem in Europe. Luxembourg: Office for Official Publications of the European Communities. <http://ar2006.emcdda.europa.eu/download/ar2006en.pdf $>$ (Version current at December 4, 2008).

3. Ghuran A, Nolan J. Recreational drug misuse: Issues for the cardiologist. Heart 2000;83:627-33.

4. Smit A, Wieling W, Voogel A, et al. Orthostatic hypotension due to suppression of vasomotor flow after amphetamine intoxication. Mayo Clin Proc 1996;71:1067-70.

5. Wijetunga M, Seto T, Lindsay J, Schatz I. Crystal methamphetamine-associated cardiomyopathy: Tip of the iceberg? J Toxicol Clin Toxicol 2003;41:981-6 